\title{
POLYMERIZATION OF ANILINE IN DIFFERENT SBA-16 SILICA HOSTS
}

\author{
Leidy Hoyos Giraldo*, Alejandro Ramirez Velez and Monica Mesa Cadavid \\ Grupo Ciencia de los Materiales, Instituto de Química, Facultad de Ciencias Exactas y Naturales, Universidad de Antioquia UdeA, \\ Calle 70 No. 52-21, Medellín, Colombia
}

Recebido em 03/02/2016; aceito em 28/03/2016; publicado na web em 06/06/2016

\begin{abstract}
Polyaniline-silica composites made with mesoporous silica have been reported to improve the mechanical properties of the free polymer. However, there are not many studies about the effect of the chemical and physical properties of the inorganic material used as hosts over the final properties of polyaniline and the composites. Here, polyaniline-silica composites, exhibiting electrical conductivity, were synthesized using different types of SBA-16 mesoporous silica as hosts. The effects of the characteristics of the hosts in the polymerization kinetic, molecular weight and electrical conductivity of the final polymer were studied. The composites showed higher electrical conductivity in comparison with polyaniline synthesized under similar conditions of this work but in the absence of silica. The use of silica allowed to obtain composites with defined morphology, which did not occur in the absence of these hosts. From the results of this work, it can be concluded that SBA-16 mesoporous silica hosts have a bifunctional role in the formation of polyaniline-silica composites: the hosts behaved like nucleation sites, which favors polymerization of high molecular weight polyaniline and they catalyzed the polymerization reaction, especially when aluminum is present in the structure of the host.
\end{abstract}

Keywords: silica hosts; SBA-16 porous materials; polyaniline-silica composite; electrical conductivity.

\section{INTRODUCTION}

An organized porous structure, large pores and uniform thickness pore walls characterize mesoporous silica materials. The first family of this kind of materials, designated like M41S, was obtained by Mobil Corporation in 1992, by using a cationic surfactant in basic medium. ${ }^{1,2}$ Since their discovery, other kinds of families of silica have been reported. ${ }^{3,4}$ The SBA-15 and SBA-16 silica type have a hexagonal and cubic porous structure, respectively. They have interconnected pores, larger pore size, higher wall thickness, thermal and mechanical stability compared with the M41S silicas. ${ }^{5}$

The SBA-16 silica is a mesoporous material with 3D cubic pore arrangement corresponding to $\operatorname{Im} 3 \mathrm{~m}$ space group. ${ }^{6,7}$ In this bodycentered-cubic structure, each mesopore is connected with its eight nearest neighbors to form a mesoporous network, which is also connected with micropores. The combination of high surface area and thermal stability with 3D structure of the SBA-16 silica allows its use as a host for the synthesis of composite materials. A 3D structure is also a desired property in electronic applications because it offers a more efficient interconnection. ${ }^{8,9}$ However, the silica is an insulator material, which has motivated the synthesis of composite materials by adsorbing electrical conductive polymers in its walls, which permitted to combine silica properties such as stiffness, thermal and mechanical stability with advantages of the polymer such as flexibility, electrical conductivity, ductility and processability. ${ }^{10}$ Polyaniline (PANI) is one of the most studied polymers in the last years and it has been used in many devices such as rechargeable batteries, ${ }^{11}$ fuel ${ }^{12,13}$ and solar cells, ${ }^{14-17}$ coatings ${ }^{18,19}$ and sensors. ${ }^{20,21}$ PANI exhibits different advantages like the simple process of synthesis, ${ }^{22}$ low cost and high electrical conductivity, which can be modulated by changing the oxidation and protonation degree. ${ }^{23}$

Some examples of PANI-silica composites include those prepared with colloidal silica, maintaining the conductivity of the polymer in a stable colloidal form and improving the mechanical behavior of the material. ${ }^{24}$ PANI-silica composites made with MCM-41 or SBA-15 silica show better electrorheology and impedance properties than the free polymer. ${ }^{25,26}$

Annunziata et $a l .{ }^{25}$ researched the effect of the presence of sodium or aluminium in the adsorption of aniline into the SBA-16 silica. But they did not worry about the polymerization process and the electrical conductivity properties of the composite materials.

Thus, our goal is to investigate the effect of the porosity (surface area and pores sizes) and chemical properties of the SBA-16 hosts on the yield and kinetic of aniline polymerization and their correlation with PANI molecular weight and conductivity properties of the composite materials. The use of hosts with large pore size and surface area favoured the polymerization rate and the efficiency of the reaction.

\section{EXPERIMENTAL}

\section{Materials}

Pluronic F-127, cetyltrimethylammonium bromide (CTABr), tetraethylorthosilicate (TEOS, 98\%), aniline (99.5\%), sodium fluoride $(\mathrm{NaF})$, hydrocloric acid $(\mathrm{HCl})$, ammonium persulfate (APS) and $\mathrm{N}$-methylpyrrolidone (NMP) were purchased from Sigma-Aldrich. Sodium aluminate $\left(\mathrm{Na}_{2} \mathrm{Al}_{2} \mathrm{O}_{4}\right)$ from Merck.

\section{Synthesis of the mesoporous silica hosts}

The reference SBA-16 material, designated as S host, was synthesized according to the reported method, ${ }^{27}$ by using a mixture of nonionic block copolymer Pluronic F-127 and CTABr surfactants as porous structure directing agents, and TEOS as silica source. The molar ratio was 1TEOS: 0.005 F127: 0.020 CTABr: $495 \mathrm{H}_{2} \mathrm{O}: 3.5 \mathrm{HCl}$. The mixture was aged at $95^{\circ} \mathrm{C}$ for 5 days. After that, the mixture was filtrated, washed and dried at $60^{\circ} \mathrm{C}$. The surfactant was removed for a calcination process at $540{ }^{\circ} \mathrm{C}$.

Synthesis of modified mesoporous silica hosts (S-NaF or S-Al)

The S-NaF material was synthesized following the same 
procedure for the $\mathrm{S}$ host obtention but adding $\mathrm{NaF}$ in the reaction mixture (1TEOS: $0.002 \mathrm{NaF}$ ).

The S-Al host was obtained by a post-synthesis alumination: the calcined $\mathrm{S}$ host. This material was treated with $0.20 \% \mathrm{wt} / \mathrm{v} \mathrm{Na}_{2} \mathrm{Al}_{2} \mathrm{O}_{4}$ aqueous solution, following the procedure described on the literature (theoretical relation $\mathrm{Si} / \mathrm{Al}=20$ ). ${ }^{28,29}$

\section{Polymerization of Aniline (ANI) in the hosts}

The hosts were activated at $200^{\circ} \mathrm{C}$ for $2 \mathrm{~h}$. Then, they were put in contact with pure liquid aniline at $25^{\circ} \mathrm{C}$ for $2 \mathrm{~h}$ ( $4 \mathrm{~g}$ ANI: $1 \mathrm{~g}$ host). The samples containing aniline adsorbed in the host were named ANI-S, ANI-S-Al or ANI-S-NaF. A solution of $1.0 \mathrm{~mol} \mathrm{~L}^{-1}$ APS was added to the mixture as initiator agent for the aniline polymerization (1 ANI: 0.26 APS molar ratio). The reaction mixture was magnetically stirred for $2 \mathrm{~h}$. The final material was filtered and washed with 0.1 mol $\mathrm{L}^{-1} \mathrm{HCl}$ and distilled water, and dried at $60^{\circ} \mathrm{C}$ for obtaining the PANI-host composite materials. They were denoted as P-S, P-S-Al and P-S-NaF, where $\mathrm{P}$ stands for the PANI polymer in each host.

\section{Characterization}

The total surface area, average pore diameter and porous volume of the hosts and PANI-host composites were calculated according to BET and BJH models from nitrogen adsorption isotherm at $77 \mathrm{~K}$, obtained with a Micromeritics ASAP 2020 apparatus. The samples were degassed at $250{ }^{\circ} \mathrm{C}$ for $12 \mathrm{~h}$ prior to analysis.

The chemical surface of the hosts was determined from Infrared analysis (FTIR) in transmittance mode on Spectrum One PerkinElmer equipment (4000-500 $\mathrm{cm}^{-1}$ ). For determining the presence of aluminum in the structure, the hosts were saturated with pyridine for $2 \mathrm{~h}$ at room temperature and their FTIR spectra were scanned in the range of $1400-1700 \mathrm{~cm}^{-1}$. The ${ }^{27} \mathrm{Al}$ solid-state nuclear magnetic resonance $\left({ }^{27} \mathrm{Al}\right.$ NMR) was recorded using a Bruker solid state spectrometer in order to determine the kind of incorporated aluminium. The spectra were recorded at $100 \mathrm{~K}$, spin rate was $8000 \mathrm{~Hz}$ and the relaxation delay was 600 s to ensure the system was completely relaxed to equilibrium.

The ANI and PANI mass percentage in the composites materials were determined by thermogravimetric analyses (TGA, Q500 TA Instruments), under air atmosphere in the ANI-hosts and PANI-hosts composites. The ANI or PANI mass percentages were calculated in dry base using the thermal event between $100-160{ }^{\circ} \mathrm{C}$ and $200-600$ ${ }^{\circ} \mathrm{C}$, respectively.

Morphology of the hosts and PANI-host composites was seen by using Scanning Electron Microscope (SEM) Philips XL-30 equipment. Before the measurements, the samples were degassed and coated with gold.

The statistics of particle sizes were determined using the ImageJ program.

The kinetic of ANI polymerization in the three different hosts were monitored by recording the temperature and $\mathrm{pH}$ changes throughout time, since the polymerization of aniline is exothermic and sulfuric acid is produced.

The average molecular weight $\left(\mathrm{M}_{v}\right)$ of the PANI polymer was determined by the intrinsic viscosity method following the report of Mark-Kuhn-Houwink-Sakurada, which consider, where $\mathrm{K}$ and $\alpha$ are constants equal to $\mathrm{K}=1.95 \times 10^{-6}, \alpha=1.36$ for the PANI and is the intrinsic viscosity ${ }^{30}$ Firstly, the interference of hosts was eliminated by washing the composite material with a $40 \% \mathrm{HF}$ solution. Solutions of PANI in NMP $\left(0.002-0.006 \mathrm{~g} \mathrm{~cm}^{-3}\right)$ were prepared by an ultrasonic treatment because the PANI is slightly soluble in NMP. ${ }^{31}$ The Ostwald viscometer was used for measuring the falling time $(\mathrm{t})$ of the solutions with different PANI concentration (c) at $30{ }^{\circ} \mathrm{C} .{ }^{30}$
The intrinsic viscosity ( was obtained from the relative viscosity $\left(\eta_{\text {rel }}=\mathrm{t}^{*} \mathrm{t}_{0}{ }^{-1}\right)$, where $\mathrm{t}_{0}$ is the falling time for the solvent. When the polymer concentration is near to zero, $\eta_{\text {rel }}$ can be related with inherent viscosity $\left(\eta_{\text {inh }}=\left(\ln \left(\eta_{\text {rel }}\right)\right) * c^{-1}\right)$ and reduced viscosity $\left(\eta_{\text {red }}\left(\eta_{\text {rel }}-1\right) * c^{-1}\right)$ for building the Kraemer ( $\eta_{\text {inh }}$ vs c) and Huggins ( $\eta_{\text {red }}$ vs c) graphs. The interception between these two graphs gives the intrinsic viscosity. The measurements were performed by duplicate.

The type of PANI was determined by UV-Vis spectroscopy for solutions of PANI in NMP, by using a PerkinElmer equipment (200-1000 nm).

For the electrical conductivity properties of the PANI-hosts composites, a paste was manually prepared by mixing an amount of polymer particles with epoxy resin. Then, the paste was compacted by using pressure for obtaining a $0.4 \mathrm{~mm}$ of thickness. The electrical conductivity of the PANI-host composites was obtained by using the Ohm's law, from potential applied (V) vs. current (I) curve, which was measured using a potentiostat-galvanostat Autolab® PGSTAT101.

\section{RESULTS AND DISCUSSION}

\section{Characterization of hosts}

Figure 1 shows the FTIR spectra of the hosts. All spectra exhibit typical absorption bands for silica materials: $3484 \mathrm{~cm}^{-1}$ (bonded $\mathrm{Si}-\mathrm{OH}$ stretching and physisorbed water) and $1121 \mathrm{~cm}^{-1}$ ( $\mathrm{Si}-\mathrm{O}-\mathrm{Si}$ asymmetric stretching). ${ }^{32}$ The signal at $1653 \mathrm{~cm}^{-1}$ is due to the presence of adsorbed water. ${ }^{28}$ Signal at $969 \mathrm{~cm}^{-1}$ and $962 \mathrm{~cm}^{-1}$ for S-NaF and $\mathrm{S}$ hosts, respectively, are assigned to asymmetric stretching of $\mathrm{Si}$-O neighboring to $\mathrm{Si}-\mathrm{OH} .{ }^{25}$ Martinez et al. ${ }^{25}$ attributed the absence of these signals to the interaction of surface silanol groups with $\mathrm{Al}$ species forming Si-O-Al bonds. This signal is not observed in the $\mathrm{S}$-Al material, indicating that the incorporation of aluminum into the silica network was accomplished. This is corroborated by the presence of $1600 \mathrm{~cm}^{-1}$ and $1446 \mathrm{~cm}^{-1}$ bands in the FTIR spectra for the pyridine adsorbed in the hosts. These bands are due to pyridine interacting with hydrogen-bonded and free weakly acidic silanol groups, respectively (Bronsted groups). ${ }^{33,34}$

The signal around $1633 \mathrm{~cm}^{-1}$ for $\mathrm{S}-\mathrm{Al}$ samples is assigned to pyridine interacting with tetrahedral or octahedral $\mathrm{Al}$ in Bronsted and Lewis sites, respectively. ${ }^{34}$ The ${ }^{27} \mathrm{Al}$ NMR was used to differentiate the coordination of the aluminium atom in the structure (Figure 2). The ${ }^{27} \mathrm{Al}$ NMR spectrum shows just a signal at $53 \mathrm{ppm}$ typically assigned to tetrahedral aluminium atoms suggesting the formation of Bronsted groups, because of the formation of Al-O-Si bonds in the structure. ${ }^{35-37}$ The presence of this aluminium confers more acidic properties to the S-Al material compared with the S and $\mathrm{S}-\mathrm{NaF}$ materials. ${ }^{38}$

The nitrogen adsorption-desorption isotherms and BJH distributions for hosts are shown on Figure 3. All isotherms are IV type with $\mathrm{H} 2$ hysteresis type. This kind of isotherm is characteristic of mesoporous materials such as SBA-16 silica, due to the interconnectivity of its pores. The S-Al and S-NaF samples exhibit isotherms with lower amount of adsorbed nitrogen and smaller surface areas than the $\mathrm{S}$ host (Table 1).

In the case of S-Al host, a partial collapse of the porous structure during the treatment with $\mathrm{Na}_{2} \mathrm{Al}_{2} \mathrm{O}_{4}$ can be responsible of the decrease of the pore volume and the surface area compared with the original $\mathrm{S}$ host. On the other hand, the differences in the porous characteristics for $\mathrm{S}$ and $\mathrm{S}-\mathrm{NaF}$ silica are due to the changes induced for the presence of $\mathrm{F}^{-}$ions in the reaction mixture. The $\mathrm{F}^{-}$species play a catalytic role, increasing the TEOS hydrolysis and the polycondensation rates. The $\mathrm{F}$ - ions also induce changes in the mechanism formation of silica 

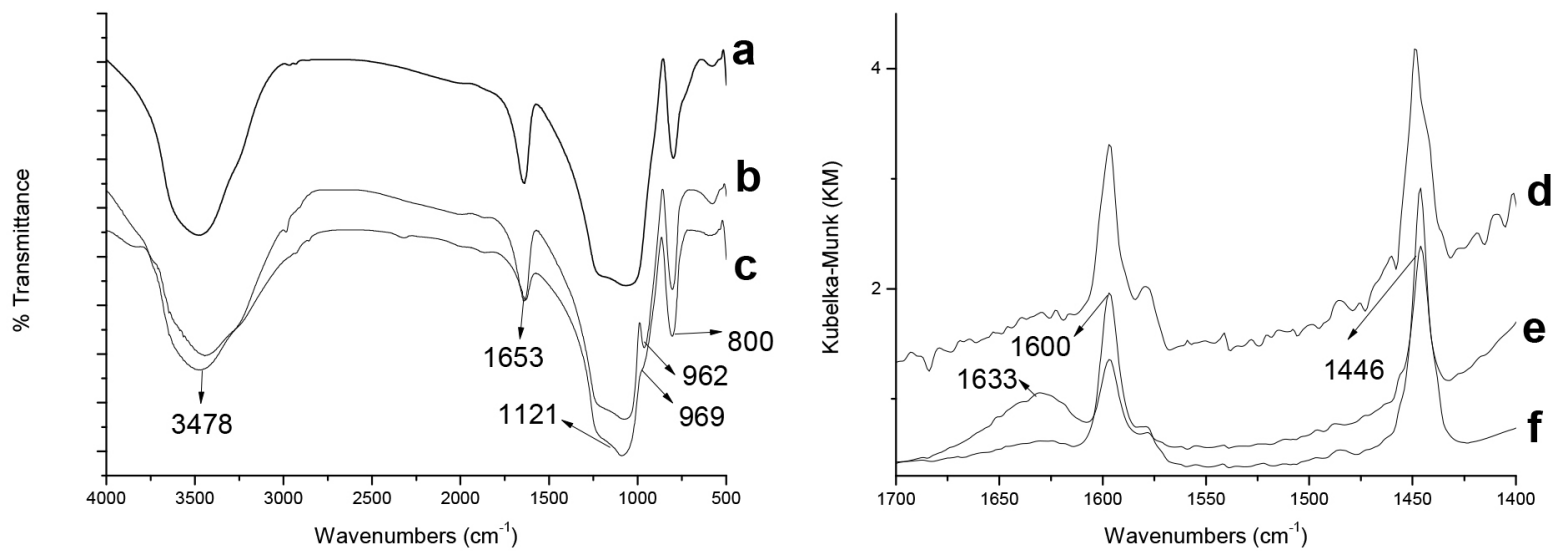

Figure 1. FTIR spectra: (a) S-Al, (b) S, (c) S-NaF hosts; and (d)S-NaF, (e) S-Al, (f) S hosts after adsorption of pyridine

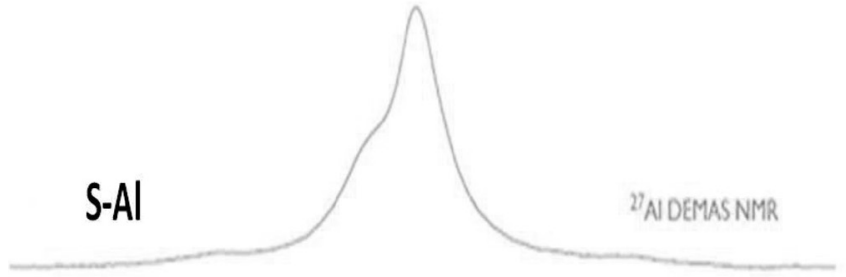

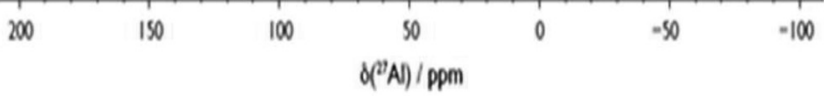

Figure 2. ${ }^{27} \mathrm{Al} N \mathrm{NM}$ spectrum for $\mathrm{S}$-Al sample

Table 1. Porous properties of samples

\begin{tabular}{lcccc}
\hline Sample & $\begin{array}{c}\text { BET Area } \\
\left(\mathrm{m}^{2} \mathrm{~g}^{-1}\right)\end{array}$ & $\begin{array}{c}\text { BJH Pore } \\
\text { diameter } \\
(\mathrm{nm})\end{array}$ & $\begin{array}{c}\text { Total Porous } \\
\text { volume } \\
\left(\mathrm{cm}^{3} \mathrm{~g}^{-1}\right)\end{array}$ & $\begin{array}{c}\text { Particle sizes } \\
(\mu \mathrm{m})\end{array}$ \\
\hline $\mathrm{S}$ & 1283.0 & 5.8 & 1.09 & $3.4 \pm 1.8$ \\
$\mathrm{P}-\mathrm{S}$ & 292.3 & 1.9 & 0.47 & \\
S-NaF & 524.0 & 4.4 & 0.66 & $0.4 \pm 0.3$ \\
P-S-NaF & 583.7 & 1.9 & 1.01 & \\
S-Al & 469.0 & 6.6 & 0.62 & $2.1 \pm 1.2$ \\
P-S-Al & 572.2 & 1.9 & 0.93 & \\
\hline
\end{tabular}

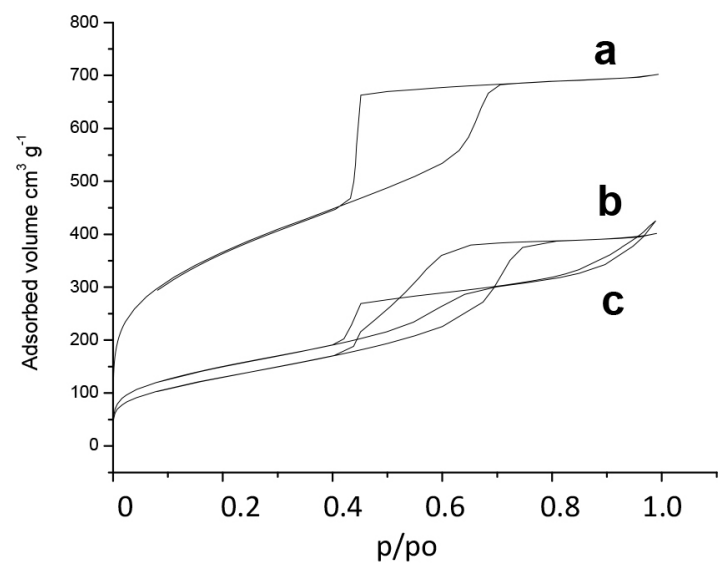

particles, because they modify the interaction between the surfactant and siliceous species. All these effects lead to the seen changes on the porous properties. ${ }^{39}$

Besides, the use of $\mathrm{NaF}$ in the synthesis leads to the formation of spherical particles in the S-NaF host (Figure 4c) with particle sizes (< $1 \mu \mathrm{m})$ smaller than those observed in the $\mathrm{S}$ and $\mathrm{S}-\mathrm{Al}$ silica materials (Figures $4 \mathrm{a}$ and $4 \mathrm{~b}$ ). Meanwhile, the alumination process does not generate changes of the particle morphology in comparison with the S silica materials (Figure 4b).

\section{Adsorption of aniline in hosts}

Figure 5 shows the TGA thermograms obtained for ANI-host composites, from which it is possible to calculate the mass percentage of incorporated aniline. In general, one loss event for the ANI-host composites is observed in the thermograms, in which the overlapping of two signals is appreciated. It could be due to the presence of aniline in the surface of the hosts and aniline inside of their pores. The later desorbs to a higher temperature.

Figure 6 summarizes the results for the mass percentage of ANI and PANI incorporated in the hosts. In theory, for the used hosts in this work, having a pore volume of $1.09-0.62 \mathrm{~cm}^{3} \mathrm{~g}^{-1}$, they could accommodate about 1.27-0.73g of ANI, which represent about 69.5-39.5 $\%$ wt ANI inside the pores. These results are obtained using the molar volume of ANI calculated by GAUSSIAN program $\left(79.45 \mathrm{~cm}^{3} \mathrm{~mol}^{-1}\right)$. The mass percentages of incorporated ANI obtained experimentally (Figure 6) are higher than theoretical values, which indicate that ANI is either inside of the pores and in the external surface area of the particles. However, it is expected that the higher quantity of ANI is

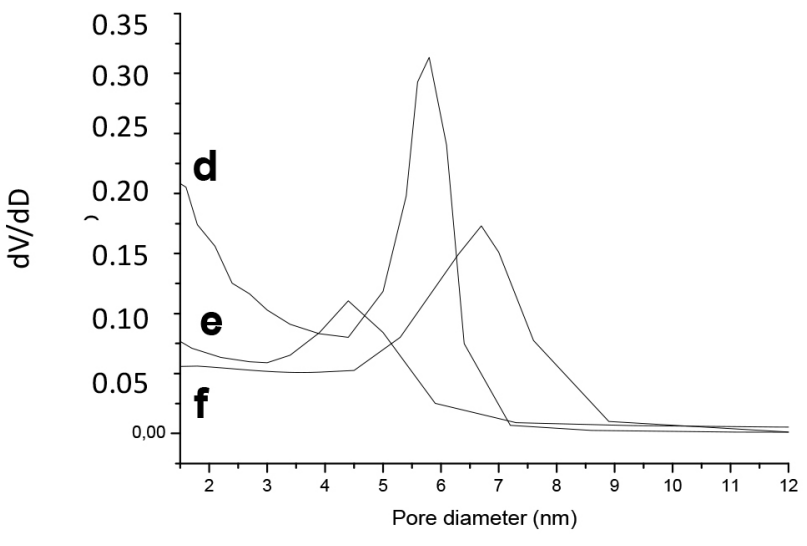

Figure 3. Nitrogen adsorption-desorption isotherms of (a) S, (b) S-Al, (c) S-NaF and BJH distributions of (d) S, (e) S-NaF, (f) S-Al of hosts 

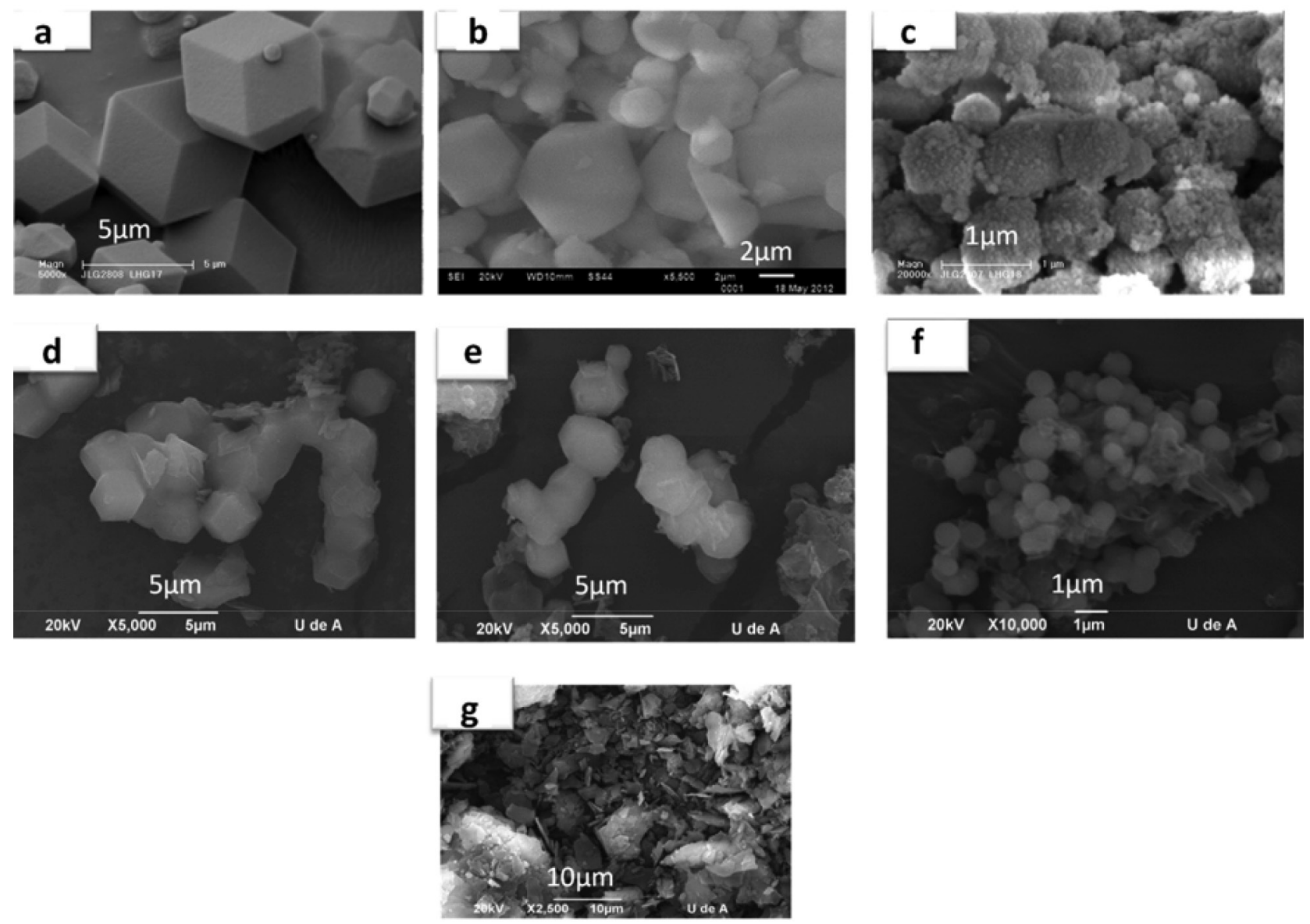

Figure 4. SEM micrographs for hosts: $S(a), S-A l(b), S-N a F(c)$; PANI-silica composites: $P-S(d), P-S-A l(e), P-S-N a F(f)$ and PANI synthesized in the absence of hosts $(g)$
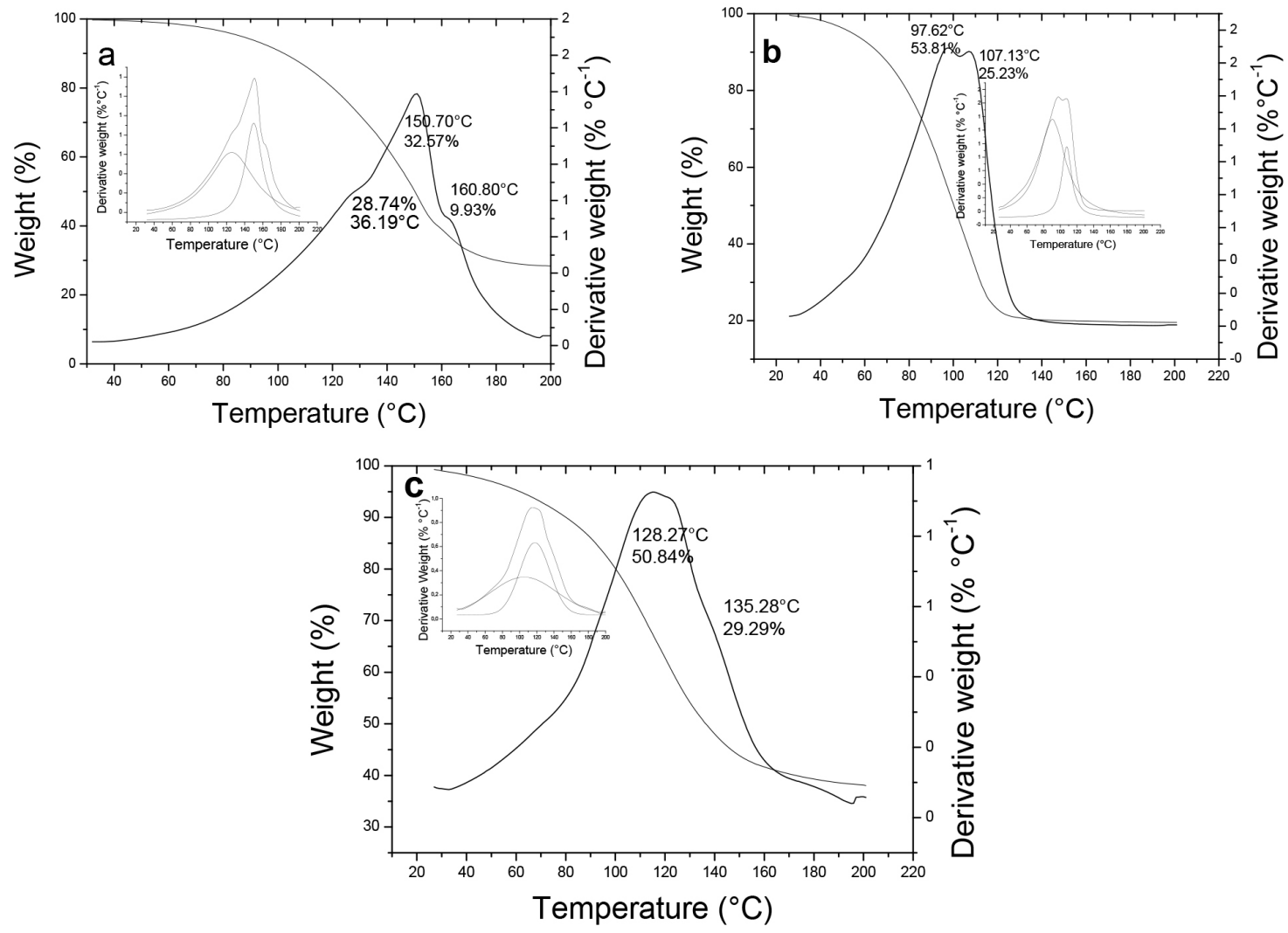

Figure 5. TGA thermograms for aniline-hosts composites materials: ANI-S (a), ANI-S-Al (b), ANI-S-NaF (c) 
inside the pores due to the high pore volume and the surface area of the hosts (Table 1).

The differences in the chemical surface of the hosts contributed to the different mass percentage of the adsorbed ANI in each host and the posterior polymerization degree (Figure 6).

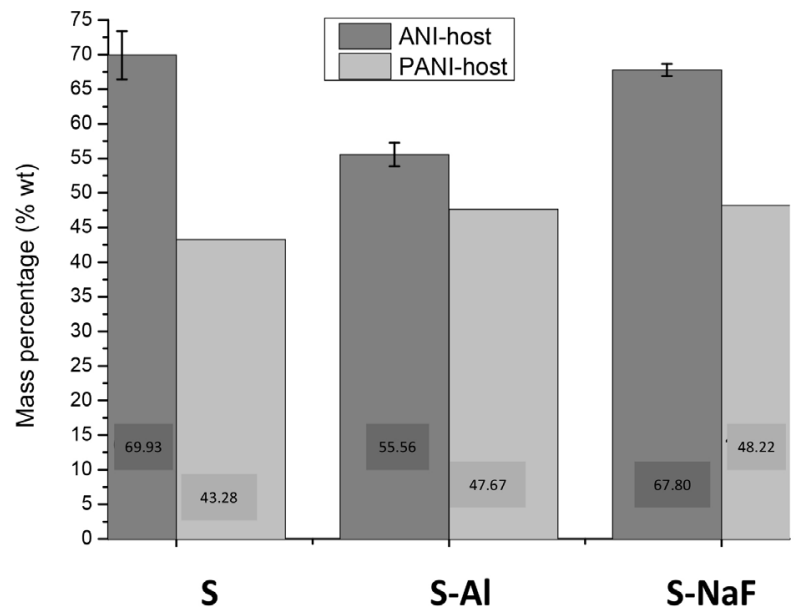

Figure 6. Mass Percentage of ANI and PANI in the S, S-Al and S-NaF hosts

\section{Polymerization of aniline in hosts}

The ANI adsorbed in the host is polymerized, resulting in PANIhost composites that have ANI mass percentage between $43-48 \%$ wt (Figure 6). The polymerization yield is higher for the P-S-NaF and $\mathrm{P}-\mathrm{S}-\mathrm{Al}$ samples than for P-S one, showing the beneficial effects of the silica modification with aluminium or $\mathrm{NaF}$.
The ANI-host and PANI-host composite FTIR spectra are compared in Figure 7 for corroborating the polymerization. The signals at $1622 \mathrm{~cm}^{-1}$ (H-N-H bending) and $1468 \mathrm{~cm}^{-1}$ (benzenoid C-C stretching) are observed for ANI-host samples indicating the presence of the aniline in the host. The absence of signals around $1600 \mathrm{~cm}^{-1}$ in the spectra for PANI-host composites and the appearance of new bands at $1445 \mathrm{~cm}^{-1}$ and $1402 \mathrm{~cm}^{-1}$ due to $\mathrm{C}=\mathrm{N}$ of head-coil and $\mathrm{N}=\mathrm{N}$ head-head polymerization, respectively, ${ }^{40,41}$ indicate the aniline polymerization.

Porous properties of the PANI-host composites are compared with the free hosts (Table 1). The decrease of the pore diameter in the PANI-host composites, compared with the respective host, (Table 1) indicates that the ANI polymerization is occurring inside the pore of the hosts. This kind of polymerization in confined systems has been observed by Stejskal. ${ }^{42}$ However, the polymerization in the external surface in the host particles cannot be completely neglected, as it is shown by the surface area and the pore volume increase in these composites materials especially for $\mathrm{P}-\mathrm{S}-\mathrm{NaF}$ and $\mathrm{P}-\mathrm{S}-\mathrm{Al}$. These results are corroborated by the SEM analysis (Figure 4). PANI-host composites showed a similar morphology to the pristine hosts, indicating that the polymerization generally resulted inside of the pores. However, the presence of imperfections in the borders of particles confirms also the presence of polymerized aniline surrounding the particles. This effect is more evident when $\mathrm{S}-\mathrm{Al}$ and $\mathrm{S}-\mathrm{NaF}$ hosts were used. It may indicate that the polymerization of ANI outside of the pores results in the formation of additional porosity, which is not dependent of the host porosity.

The obtained PANI in the composites is mainly emeraldine type (Figure 8). The use of $\mathrm{HCl}$ for washing the PANI-host composites generates a doped emeraldine with deprotonated oxidized repeat units, resulting in a $\varpi$ delocalization in the polymer backbone. ${ }^{43}$ Two absorption peaks for the UV spectra are observed (Figure 8). The first
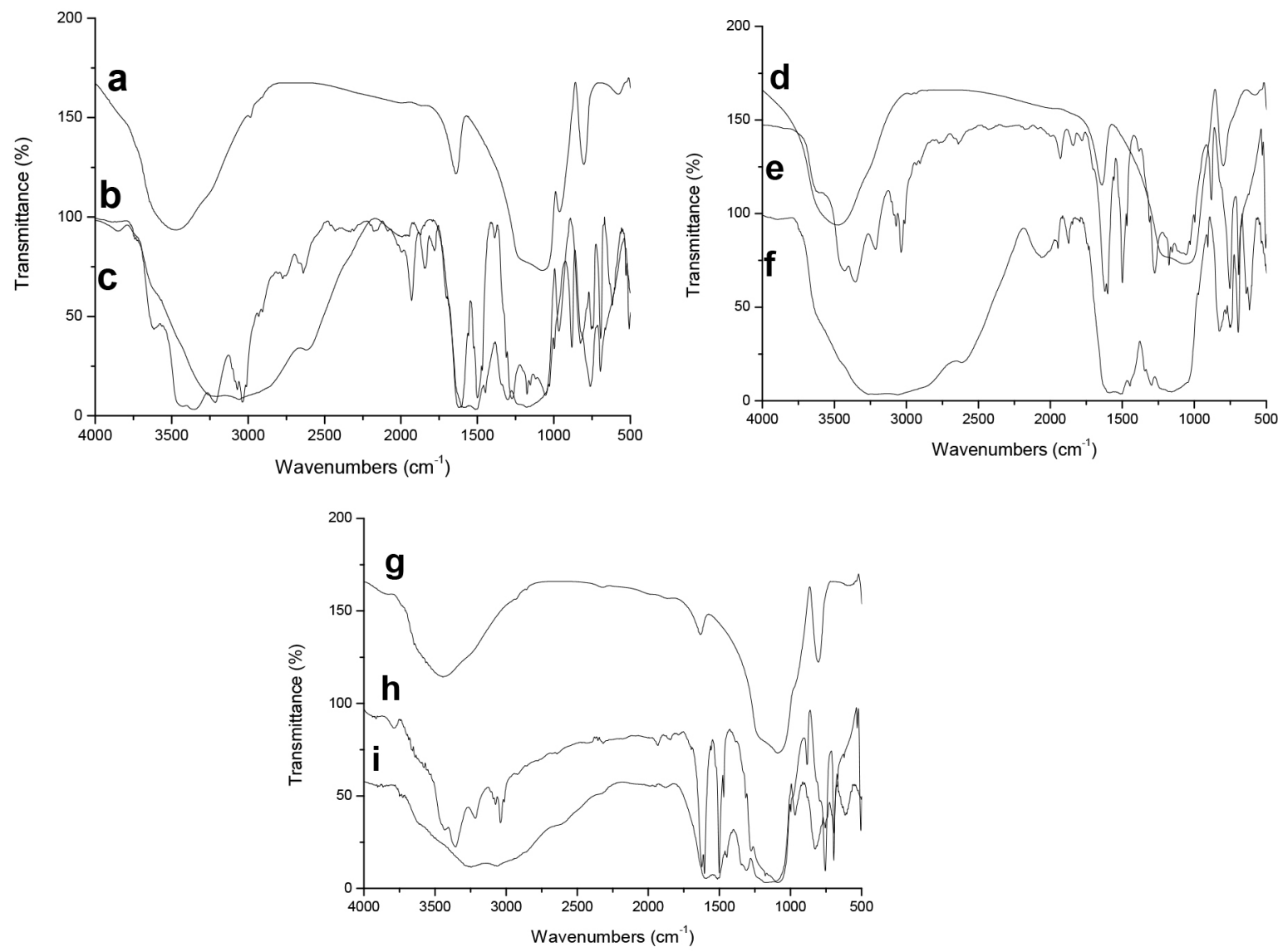

Figure 7. FTIR of (a) S, (b) P-S, (c) ANI-S, (d) S-Al, (e) ANI-S-Al, (f) P-S-Al, (g) S-NaF, (h) ANI-S-NaF, (i) P-S-NaF 
peak around $293 \mathrm{~nm}$ is associated with the forbidden transition to an excited homopolar state in the substituted benzene rings. The second peak $(373 \mathrm{~nm})$ is associated with polyaniline in state of emeraldine assigned to $\pi \rightarrow \pi^{*}$ excitation of the substituted benzenoid ring. ${ }^{44,45}$

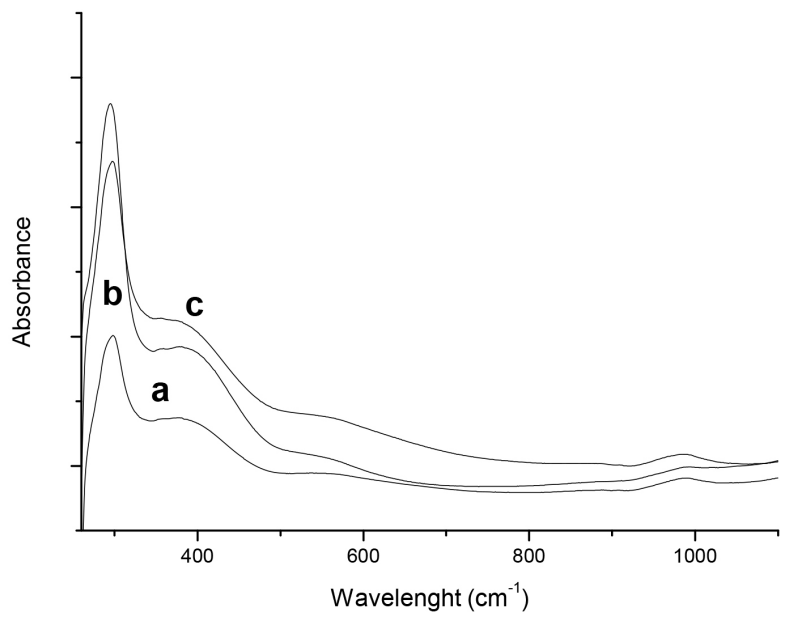

Figure 8. UV-Vis spectra of PANI-hosts materials: (a) P-S, (b) P-S-Al, (c) $\mathrm{P}-\mathrm{S}-\mathrm{NaF}$

Effect of the host in the polymerization kinetic of aniline and molecular weight of polyaniline

Polymerization of aniline mediated by APS is an exothermic process and protons are produced, increasing the acidity in the reaction medium. Thus, the polymerization reaction was followed by the temperature and $\mathrm{pH}$ changes, in function of the presence of the
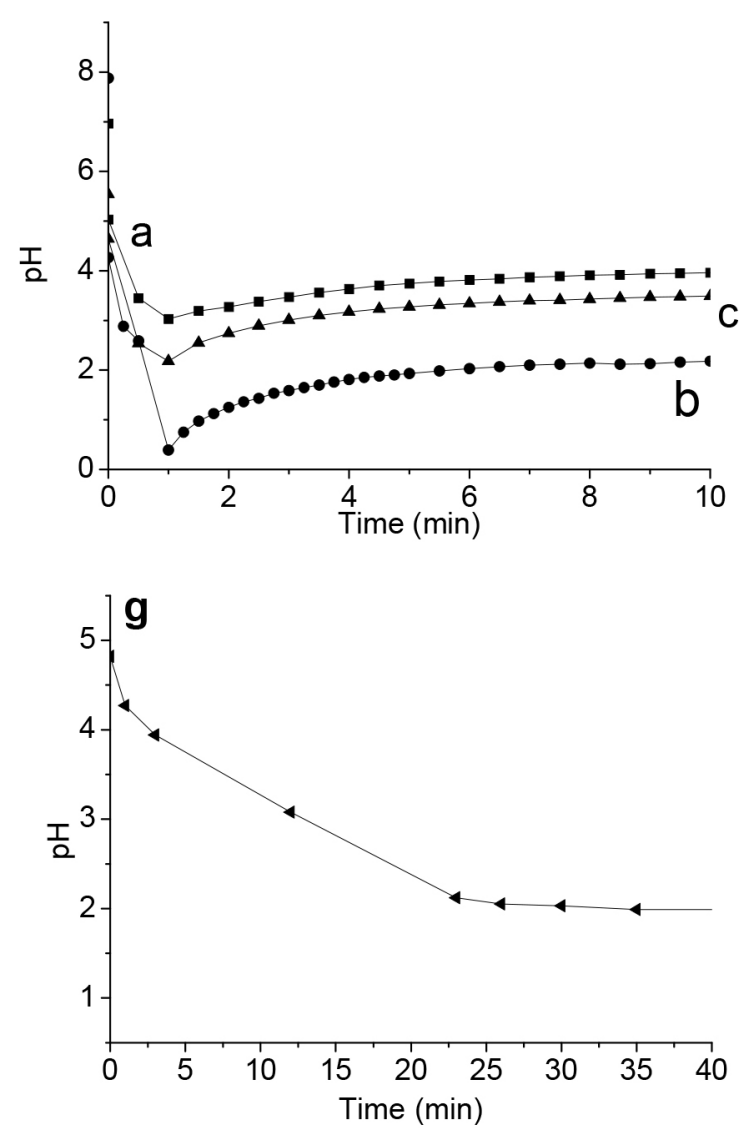

host in the reaction system (Figure 9). According to the $\mathrm{pH}$ at the beginning of the process $(\mathrm{pH}>5)$ and taking into account the $\mathrm{pKa}$ of aniline (4.6), neutral aniline molecules are the main species in the reaction mixture.

When the APS solution is added to the reaction mixture, a fast $\mathrm{pH}$ drop is observed with or without hosts, indicating the absence of the induction period (Figure 10). The amine group of the aniline monomers is easily oxidized because they exhibit low oxidation potential under the conditions of this work. Temperature has a monotonic increase. The amine groups are oxidation centers, and they attack the aniline molecule to continue with the polymerization. Drop of the $\mathrm{pH}$ is associated with consume of aniline and the production of $\mathrm{H}^{+}$ions, due to the attachment of aniline to other aniline molecule. It is noticeable that the final is a lower $\mathrm{pH}$ when the polymerization is made in the presence of the S-Al host (Table 2), due to the acidic properties of this material, which contributes to the extensive polymerization of PANI. At the end of the polymerization process, a little increase of $\mathrm{pH}$ was observed (Figure 9) because the remaining aniline reacts with the acid and a neutralization reaction occurs. ${ }^{46}$

The average molecular weight of polymer fraction ( $\mathrm{M} v$, in grams per mole), determined from intrinsic viscosity, are given in Table 2. The use of hosts favor the formation of polymer with high molecular weight in comparison with the PANI synthesized in the absence of them (Table 2). These results indicate that the surface area of the hosts behaves like nucleation sites, which favors polymerization of aniline. On the other hand, the hosts can behave as catalysts accelerating the polymerization process of the aniline, as it is seen in the rate constants (Table 2). This catalytic effect is more important with the S-Al host because of the presence of tetrahedral aluminium, which is associated with acidic sites. The catalitic properties have been also reported for other aluminosilicates. ${ }^{38}$
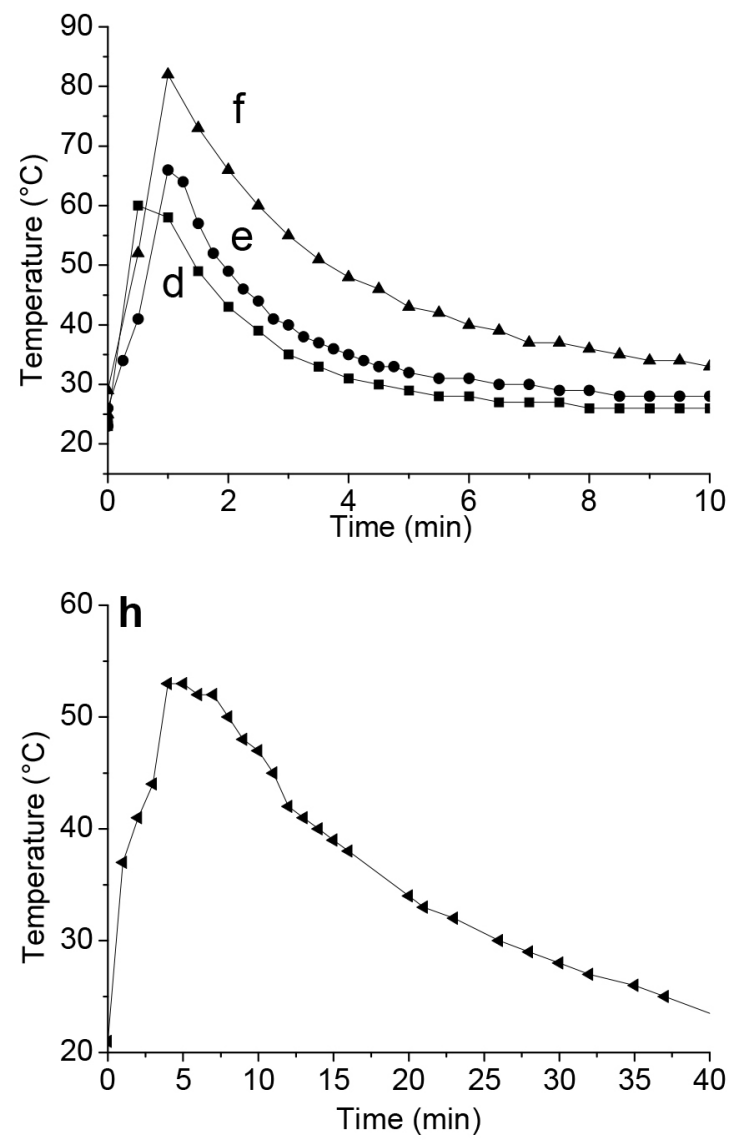

Figure 9. $p H$ and temperature profiles of $(a, d)$ PANI-S, $(b, e)$ PANI-S-Al, $(c, f)$ PANI-S-NaF and PANI without hosts $(g, h)$ 
Table 2. Characteristics of the polymerization reaction (final $\mathrm{pH}$, rate constant), PANI molecular weight and electrical conductivity of PANI-host composites obtained by using different SBA-16 silica hosts

\begin{tabular}{lcccc}
\hline Hosts & Final pH & $\begin{array}{c}\text { Molecular } \\
\text { weight }\left(\mathrm{M}_{\mathrm{v}}\right) \\
(\mathrm{KDa})\end{array}$ & $\begin{array}{c}\text { Rate constant } \\
\left(\mathrm{mol}^{-1} \mathrm{~L} \mathrm{~s}^{-1}\right) \\
\times 10^{-2}\end{array}$ & $\begin{array}{c}\text { Conductivity } \\
\left(\mathrm{S} \mathrm{cm}^{-1}\right)\end{array}$ \\
\hline $\mathrm{S}$ & 3.03 & $697.0 \pm 2.0$ & 20 & $1.2 \times 10^{-05}$ \\
S-Al & 0.39 & $183.3 \pm 7.8$ & 260 & $6.6 \times 10^{-07}$ \\
S-NaF & 2.18 & $332.3 \pm 14.3$ & 30 & $2.4 \times 10^{-05}$ \\
None* & 1.76 & $4.08 \pm 6.3$ & 6.4 & $1.6 \times 10^{-3}$ \\
\hline
\end{tabular}

*This process was made in the absence of host.

\section{Electrical conductivity of the PANI-host composites}

The electrical conductivity of PANI-host composites is obtained from the scan of current vs potential sweeps, applying the Ohm's law (Figure 10) (V=R.I).

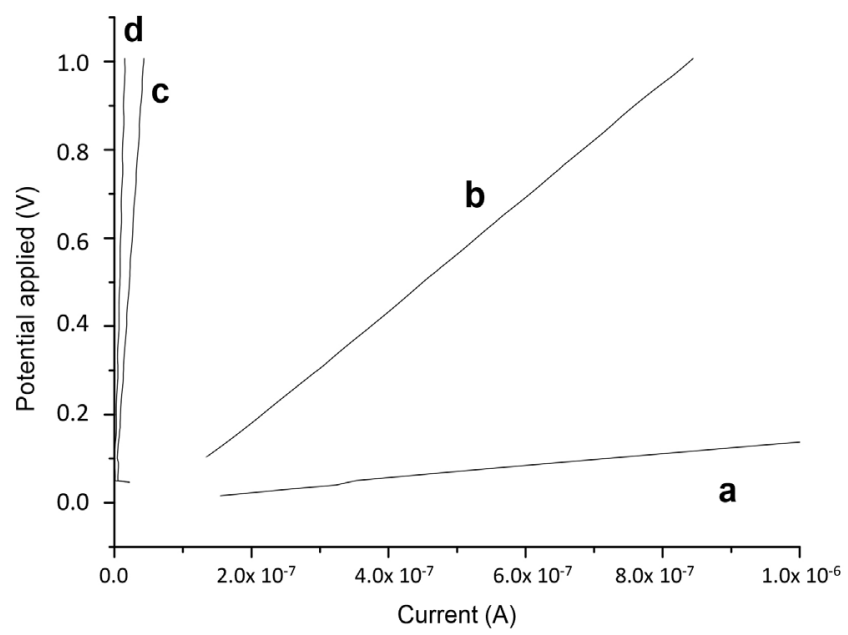

Figure 10. Current vs. potential applied for (a) PANI without host, (b) P-S, (c) P-S-Al and (d) P-S-NaF pellet

The PANI-host composites exhibit electrical conductivity higher than $10^{-10} \mathrm{~S} \mathrm{~cm}^{-1}$, which is higher than the values reported for other PANI synthesized in the literature. ${ }^{46}$ The presence of hosts decreased the electrical conductivity values of the PANI-host composites compared with the free PANI, which is expected since the silica is an insulating material. The lower electrical conductivity was obtained when S-Al hosts was used. This result is attributed to the low molecular weight of the PANI when this host was used, corroborating the dependence of the electrical conductivity with the molecular weight. ${ }^{46}$

The electrical conductive characteristic of these composite materials confirms that emeraldine is the PANI form obtained here, as previously discussed with the UV results. The conductivity of this kind of PANI is attributed to the protonation of the polymer and the partial oxidation system due to the doping of PANI with $\mathrm{HCl}$.

\section{CONCLUSIONS}

In general, the polyaniline was formed into the pores of hosts, although some imperfections in the particles of the polyaniline- host composites were observed by SEM.

The use of hosts favored to obtain a high molecular weight polymer in comparison with the polyaniline synthesized in the absence of hosts. Therefore, the hosts behave like nucleation sites, which favors polymerization of aniline.

The polymerization is catalyzed by the presence of hosts, increasing the polymerization rate constant. This effect is more evident when aluminium is in the host, conferring acidic properties to the host.

Due to the emeraldine form, with high molecular weight, present in the polyaniline-host composites, these materials are promissory for being used in applications requiring a material with high electrical conductivity combined with the thermal and mechanical properties conferred by the presence of silica.

\section{ACKNOWLEDGEMENTS}

The authors thank Dr D. Lee in the CEA institute for the NMR measurements.

Leidy Hoyos thanks COLCIENCIAS for her PhD scholarship: Francisco José de Caldas, 2010.

\section{REFERENCES}

1. Beck, J. S.; Vartuli, J. C.; Roth, W. J.; Leonowicz, M. E.; Kresge, C. T.; Schmitt, K. D.; Chu, C. T. W.; Olson, D. H.; Sheppard, E. W.; McCullen, S. B.; Higgins, J. B.; Schlenker, J. L.; J. Am. Chem. Soc. 1992, 114, 10834.

2. Wang, Q.; Shantz, D. F.; J. Solid State Chem. 2008, 181, 1659.

3. Ciesla, U.; Schüth, F.; Microporous Mesoporous Mater. 1999, 27, 131.

4. Jaroniec, M.; Kruk, M.; Jaroniec, C. P.; Sayari, A.; Adsorption 1999, 5, 39.

5. Van Der Voort, P.; Benjelloun, M.; Vansant, E. F.; J. Phys. Chem. B 2002, 106, 9027.

6. Mesa, M.; Sierra, L.; Guth, J. L.; Microporous Mesoporous Mater. 2008, 112,338 .

7. Zhao, D.; Huo, Q.; Feng, J.; Chmelka, B. F.; Stucky, G. D.; J. Am. Chem. Soc. 1998, 120, 6024.

8. Liu, J.; Xie, C.; Dai, X.; Jin, L.; Zhou, W.; Lieber, C. M.; Proc. Natl. Acad. Sci. 2013, 110, 6694.

9. Javey, A.; Nam, Friedman, R. S.; Yan, H.; Lieber, C. M.; Nano Lett. 2007, 7, 773 .

10. Zou, H.; Wu, S.; Shen, J.; Chem. Rev. 2008, 108, 3893.

11. MacDiarmid, A. G.; Yang, L. S.; Huang, W. S.; Humphrey, B. D.; Synth. Met. 1987, 18, 393.

12. Cindrella, L.; Kannan, A. M.; J. Power Sources 2009, 193, 447.

13. Chen, C.-Y.; Garnica-Rodriguez, J. I.; Duke, M. C.; Costa, R. F. D.; Dicks, A. L.; da Costa, J. C. D.; J. Power Sources 2007, 166, 324.

14. Xiao, Y.; Lin, J.-Y.; Wang, W.-Y.; Tai, S.-Y.; Yue, G.; Wu, J.; Electrochim. Acta 2013, 90, 468.

15. Tan, F.; Qu, S.; Wu, J.; Wang, Z.; Jin, L.; Bi, Y.; Cao, J.; Liu, K.; Zhang, J.; Wang, Z.; Sol. Energy Mater. Sol. Cells 2011, 95, 440.

16. Li, Q.; Wu, J.; Tang, Q.; Lan, Z.; Li, P.; Lin, J.; Fan, L.; Electrochem. Commun. 2008, 10, 1299.

17. Chen, J.; Li, B.; Zheng, J.; Zhao, J.; Jing, H.; Zhu, Z.; Electrochim. Acta 2011, 56, 4624.

18. Mirmohseni, A.; Oladegaragoze, A.; Synth. Met. 2000, 114, 105.

19. Kalendová, A.; Veselý, D.; Stejskal, J.; Prog. Org. Coat. 2008, 62, 105.

20. Sadek, A. Z.; Wlodarski, W.; Kalantar-Zadeh, K.; Baker, C.; Kaner, R. B.; Sens. Actuators, A 2007, 139, 53.

21. Li, Z.-F.; Blum, F. D.; Bertino, M. F.; Kim, C.-S.; Sens. Actuators, B 2013, 183, 419.

22. Stejskal, J.; Gilbert, R. G.; Pure Appl. Chem. 2002, 74, 857.

23. Li, N.; Li, X.; Geng, W.; Zhang, T.; Zuo, Y.; Qiu, S.; J. Appl. Polym. Sci. 2004, 93, 1597.

24. Armes, S. P.; Gottesfeld, S.; Beery, J. G.; Garzon, F.; Agnew, S. F.; Polymer 1991, 32, 2325. 
25. Martínez, M. L.; Luna D’Amicis, F. A.; Beltramone, A. R.; Gómez Costa, M. B.; Anunziata, O. A.; Mater. Res. Bull. 2011, 46, 1011.

26. Cho, M. S.; Choi, H. J.; Ahn, W.-S.; Langmuir 2004, 20, 202.

27. Sierra, L.; Mesa, M.; Ramirez, A.; Lopez, B.; Gut, J. L.; In Studies in Surface Science and Catalysis; van Steen, E., Claeys, I. M., Callanan, L. H., eds.; Elsevier, 2004.

28. Eimer, G. A.; Pierella, L. B.; Monti, G. A.; Anunziata, O. A.; Catal. Lett. 2002, 78, 65 .

29. Anunziata, O. A.; Martínez, M. L.; Costa, M. G.; Mater. Lett. 2010, 64, 545.

30. Hamidi, N.; Sealeya, L.; Hamidi, B.; IJAST 2012, 2, 120.

31. Tang, S.-J.; Wang, A.-T.; Lin, S.-Y.; Huang, K.-Y.; Yang, C.-C.; Yeh, J.-M.; Chiu, K.-C.; Polym. J. 2011, 43, 667.

32. Smith, A. L.; Spectrochim. Acta 1960, 16, 87.

33. Zhang, W.; Smirniotis, P. G.; Gangoda, M.; Bose, R. N.; J. Phys. Chem. B 2000, 104, 4122.

34. Ramírez, A.; Lopez, B. L.; Sierra, L.; J. Phys. Chem. B 2003, 107, 9275.

35. Koekkoek, A. J. J.; van Veen, J. A. R.; Gerrtisen, P. B.; Giltay, P.; Magusin, P. C. M. M.; Hensen, E. J. M.; Microporous Mesoporous Mater. 2012, $151,34$.
36. Anunziata, O. A.; Beltramone, A. R.; Martínez, M. L.; Belon, L. L.; J. Colloid Interface Sci. 2007, 315, 184.

37. Gómez-Cazalilla, M.; Mérida-Robles, J. M.; Gurbani, A.; Rodríguez-Castellón, E.; Jiménez-López, A.; J. Solid State Chem. 2007, 180, 1130.

38. Anand, R.; Maheswari, R.; Hanefeld, U.; J. Catal. 2006, 242, 82.

39. Voegtlin, A. C.; Ruch, F.; Guth, J. L.; Patarin, J.; Huve, L.; Microporous Mater. 1997, 9, 95.

40. Colomban, P.; Efremova, A.; Regis, A.; Vendange, V.; Gruger, A.; Badot, J. C.; Microporous Mater. 1995, 4, 65.

41. Šed nková, I.; Trchová, M.; Stejskal, J.; Polym. Degrad. Stab. 2008, 93 , 2147.

42. Stejskal, J.; Trchová, M.; Fedorova, S.; Sapurina, I.; Zemek, J.; Langmuir 2003, 19, 3013.

43. Chiang, J.-C.; MacDiarmid, A. G.; Synth. Met. 1986, 13, 193.

44. Monkman, A. P.; Adams, P.; Synth. Met. 1991, 41, 891.

45. Huang, W. S.; MacDiarmid, A. G.; Polymer 1993, 34, 1833.

46. Sapurina, I.; Stejskal, J.; Polym. Int. 2008, 57, 1295. 